\title{
eCommons@AKU
}

THE AGA KHAN UNIVERSITY

Institute for Educational Development

January 2003

\section{School leadership in Pakistan: Exploring the headteacher's role}

Tim Simkins

School of Education, Sheffield Hallam University, UK

Charles Sisum

School of Education, Sheffield Hallam University, UK

Muhammad Memon

Aga Khan University

Follow this and additional works at: http://ecommons.aku.edu/pakistan_ied_pdck

Part of the Elementary and Middle and Secondary Education Administration Commons, Elementary Education and Teaching Commons, and the Secondary Education and Teaching Commons

\section{Recommended Citation}

Simkins, T., Sisum, C., \& Memon, M. (2003). School leadership in Pakistan: Exploring the headteacher's role. School Effectiveness and School Improvement: An International Journal of Research, Policy and Practice, 14(3), 275-291. 
This article was downloaded by: [INASP - Pakistan (PERI)]

On: 11 September 2012, At: 04:03

Publisher: Routledge

Informa Ltd Registered in England and Wales Registered Number: 1072954

Registered office: Mortimer House, 37-41 Mortimer Street, London W1T 3J H, UK

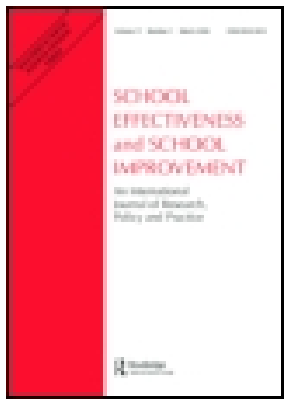

\section{School Effectiveness and School Improvement: An International J ournal of Research, Policy and Practice}

Publication details, including instructions for authors and subscription information:

http:// www. tandfonline.com/loi/ nses20

\section{School Leadership in Pakistan: Exploring the Headteacher's Role}

Tim Simkins, Charles Sisum \& Muhammad Memon

Version of record first published: 09 Aug 2010.

To cite this article: Tim Simkins, Charles Sisum \& Muhammad Memon (2003): School Leadership in Pakistan: Exploring the Headteacher's Role, School Effectiveness and School Improvement: An International J ournal of Research, Policy and Practice, 14:3, 275-291

To link to this article: http:// dx. doi.org/ 10.1076/ sesi. 14.3.275. 15841

\section{PLEASE SCROLL DOWN FOR ARTICLE}

Full terms and conditions of use: http://www.tandfonline.com/page/terms-andconditions

This article may be used for research, teaching, and private study purposes. Any substantial or systematic reproduction, redistribution, reselling, loan, sublicensing, systematic supply, or distribution in any form to anyone is expressly forbidden.

The publisher does not give any warranty express or implied or make any representation that the contents will be complete or accurate or up to date. The accuracy of any instructions, formulae, and drug doses should be independently verified with primary sources. The publisher shall not be liable for any loss, actions, claims, proceedings, demand, or costs or damages whatsoever or howsoever caused arising directly or indirectly in connection with or arising out of the use of this material. 


\title{
School Leadership in Pakistan: Exploring the Headteacher's Role
}

\author{
Tim Simkins ${ }^{1}$, Charles Sisum ${ }^{1}$, and Muhammad Memon ${ }^{2}$ \\ ${ }^{1}$ School of Education, Sheffield Hallam University, UK, and ${ }^{2}$ Institute for Educational \\ Development, The Aga Khan University, Karachi, Pakistan
}

\begin{abstract}
There is a good deal of consensus in the literature about the key role of leadership - especially that of the headteacher - in facilitating school improvement. Yet much of the research in this area has taken place in Western industrialised countries. This article explores the issue of headship in the context of schools in a specific developing country context, that of Pakistan. Drawing on 2 studies of the experience of headteachers in Karachi, the article identifies and explores the key variables that may contribute to a sense of personal efficacy for these heads, namely the expectations generated by the national or community culture, the powers and accountabilities generated by the school system in which they work, and their own individual personalities and histories.
\end{abstract}

\section{INTRODUCTION}

There seems to be a consensus in the literature that effective leadership is a key factor in school improvement. Yet the bulk of research into school leadership has taken place in Western industrialised countries. How far do the assertions and models of school leadership developed there pertain to the societies and cultures of the developing world? How do headteachers in the latter contexts lead or manage change and bring about "improvement." What may findings from studies largely undertaken in the industrialised West

Address correspondence to: Tim Simkins, School of Education, Sheffield Hallam University, Collegiate Campus, Sheffield S10 2BP, UK. Tel.: +44 114225 2325. Fax: +44 1142252323. E-mail: t.j.simkins@shu.ac.uk

Manuscript submitted: October 28, 2001

Accepted for publication: December 9, 2002 
have to suggest about the way we understand headship and approach the preparation and professional development of headteachers in differing cultures across the world?

This article seeks to address some of these questions in the education context of Pakistan. It begins by reviewing some key ideas about educational leadership and their potential applicability to the contexts of developing countries. It then proceeds to consider the nature of school leadership in the context of the Pakistani educational system, drawing on two studies that explored the experiences of a number of headteachers as they attempted to lead and manage change in their particular cultural and organisational settings. Finally we attempt to develop an understanding of those variables which determine the possibility of effective school leadership in different cultural settings.

\section{SCHOOL LEADERSHIP AND MANAGEMENT IN INTERNATIONAL CONTEXT}

The role of leadership and management in schools in developing countries is an underresearched area. One of the reasons for this may be that much of the effort for educational improvement in such countries has been focused on topdown, system-wide change rather than change at the level of the individual school. Such system-wide change has tended to emphasise the disciplines of planning and finance, rather than those of governance and management that are likely to be the key to the effective institutionalisation of change at grassroots level. Also, there is often a presumption that within the highly bureaucratised education systems of many developing countries the role of headteachers, let alone that of others with managerial roles in schools, is relatively insignificant. Such people are essentially seen as functionaries operating at a fairly low level within a multilayered hierarchy: The main levers of change are assumed to lie elsewhere with central administrators and planners.

This view, however, is no longer tenable, if it ever was. There is increasing recognition that school improvement requires effective management at school level. One reason for this is the perceived capacity of those close to the point where policies are expected to have their impact to resist change imposed from above. Increasingly, however, more positive reasons for giving greater 
attention to school-level management are being put forward. For example, De Grauwe (2000, p. 1) argues that:

Much research has demonstrated that the quality of education depends primarily on the way schools are managed, more than on the abundance of available resources, and that the capacity of schools to improve teaching and learning is strongly influenced by the quality of leadership provided by the headteacher.

This view implies a move away from the "policy-mechanic" paradigm, which seeks standard system-wide solutions to educational improvement built around key resource inputs, and towards a "classroom-culturalist" model which emphasises the importance of change processes managed at the level of the school (Fuller \& Clarke, 1994). This latter policy discourse argues that, if educational improvement is to be achieved, the prime responsibility must be placed with schools, which must be held accountable for the educational outcomes that they achieve. To enable schools to fulfil this task, there has to be decentralisation of management responsibilities to the school site and, in such a scenario, the leadership role of the headteacher is critical and requires new non-traditional managerial skills (De Grauwe, 2000).

However, as with other arguments about educational policy, these propositions first emerged in developed countries, especially those of the English-speaking world - the United Kingdom, North America, Australia, and New Zealand. Their relevance and feasibility for developing countries remains to be tested to any substantial degree, although they are increasingly influential among aid donors (Department for International Development [DfID], 1999; World Bank, 1995). Proposals for decentralisation take various forms (Lauglo, 1995). Some empower headteachers within the context of loosened hierarchies of control; others place the emphasis on the empowerment of parents through school boards or similar bodies at school level. However, their implementation raises many difficult issues (Govinda, 1997; Therkildsen, 2000). Despite the arguments for decentralisation, traditional modes of bureaucratic organisation remain ingrained in many developing country contexts. Even where decentralisation policies have been attempted, implementation has often been hampered because insufficient attention has been given either to enhancing the understanding among key administrators of the values underpinning such policies or to strengthening the implementation capacity of local managers, especially those at school level (De Grauwe, 2000). 
The issue of effective management by headteachers and other senior staff of schools in developing countries, however, raises wider issues concerning the nature of school improvement more generally and the ways in which effective leadership and management can contribute to it. Virtually all the available literature on school effectiveness and school improvement - again drawn primarily from the experience of developed countries - emphasises the role of leadership, particularly that of the principal, in achieving, maintaining, and improving school quality. This literature emphasises various models of leadership, but particular models have come to dominate in recent years. These models, which draw on general concepts of "transformational" leadership (Bass, 1985; Burns, 1978; Leithwood, Tomlinson, \& Genge, 1996), as well as education-specific ideas about "instructional leadership" (Southworth, 2002), place a strong emphasis on the role of leader in setting a vision for the school, typically focused around improved teaching and learning, and effectively inspiring and stimulating others in a commitment to the pursuit of this vision. Some international studies outside education have suggested that transformational qualities are seen as key aspects of "good" leadership in most cultural contexts (Den Hartog, House, Hanges, RuizQuintanilla, \& Dorfman, 1999). In other words, unlike some other styles of leadership, they are not culture specific. However, such views are not uncontested. First, approaches to leadership that overemphasise the role of inspirational individual leaders are increasingly being challenged in the educational leadership literature by models which emphasise more invitational and dispersed approaches to leadership (Gronn, 1999; Stoll \& Fink, 1996). Secondly, and of particular relevance for this article, there is a growing concern about the degree to which concepts and, especially, prescriptions can be easily translated from one cultural context to another (Dimmock \& Walker, 1998; Hallinger \& Leithwood, 1996). Certainly it seems unlikely that leadership is a culturally neutral concept (Koopman, Den Hartog, \& Konrad, 1999 , p. 504) and a number of writers about the education systems of developing countries have expressed considerable doubts about the degree to which headteachers in many such countries either do, or might be expected to, act effectively as transformational leaders in their schools (Ali, Qasim, Jaffer, \& Greenland, 1993; Memon, 1998; Warwick \& Reimers, 1995). The reasons for this are various. One, already referred to, lies in the highly bureaucratic and hierarchical structures and rules which govern most school systems, especially those in the Government sector. Another relates to the limited professional training and socialisation experienced by most teachers and, indeed, by many 
principals. Yet another is associated with national cultures which may encourage dependency, autocratic management styles, and aversion to risk (Hofstede, 1980, 1991; Shaw, 1998; Shaw \& Welton, 1996). Our research in Pakistan was designed to explore some of these issues.

\section{THE CONTEXT OF THE STUDIES}

Education in Pakistan is delivered through a number of education systems. The structure of the public school system, which educates the large majority of school students, is similar to that of many developing countries, especially in Asia. It is based on a "top-down" bureaucratic model with schools in the public sector controlled through centralised policy decisions. The federal Ministry of Education is responsible for formulating education policies and plans with provincial Governments acting as implementing agencies rather than taking independent initiatives for education development in their respective provinces. The system is characterised by the kind of bureaucratic inertia described earlier. Government schools face perpetual challenges of low levels of resourcing and poor quality of provision and the majority of school headteachers are effectively receivers of policy decisions rather than playing an active role in school development for quality improvement. During the last 3 years, some structural and policy reforms have been designed to replace the centralised education system with a more decentralised one. This is potentially a major paradigm shift in policy. However, these developments are at a very early stage and it remains to be seen how successful they will be.

Alongside the Government system, and partly in response to its inadequacies, an enormous variety of non-Government schools and school systems have arisen run both by non-profit-making, often community-based, trusts and by private entrepreneurs. During the last 2 decades, this sector has made substantial investment in education in urban and semi-urban areas, although the public sector is still catering to the needs of the vast majority of population in general and in rural areas in particular.

Schools in both public and private sectors are managed by untrained headteachers who have been hired on the basis of teaching experience rather than management and administration experience. Recognising the need for the professional development of headteachers, Pakistan's various education policies have proposed the recruitment of trained and qualified headteachers in public sector schools. However, this has made little headway nationally. 


\section{EXPLORING HEADSHIP IN PAKISTAN}

Ribbins and Gronn (2000) suggest a number of ways in which headship might be explored: situated portrayals of individual heads based on their own accounts; drawing on multiple perspectives from members of the head's role set; and relating these to information on heads' behaviour drawn from observational and other data. We have undertaken two studies of headship in Pakistan.

Our first study focused primarily on the first perspective, drawing on interview data with six headteachers from Government and private secondary schools in Karachi (Simkins, Garrett, Memon, \& Nazir Ali, 1998). The major finding of that study was that the nature of the school system in which a head worked had significant implications for how they saw their role and how they played it. In particular, the school system context within which Government and non-Government heads worked differed systematically in a number of ways:

- Government heads worked within a governance regime dominated by relatively bureaucratic rules and structures, whereas non-Government heads were subject primarily to the direct and personal influence of trustees and system managers.

- Non-Government heads generally had considerable powers over the management of staffing (including appointments, discipline, and in some cases pay) and finance, whereas Government heads had no such powers.

- Non-Government schools were structured through salary-differentiated hierarchies of deputy heads and posts of responsibility such as heads of department, whereas Government school structures were flat, with no formal posts of responsibility other than "teachers in charge" who received no extra remuneration for playing these roles.

Associated with these system differences were a number of differences in the ways in which heads in the two sectors saw and played their roles. Thus Government heads managed their teaching staff through direct supervision exercised through face-to-face contact and tours of the school. NonGovernment heads, in contrast, operated through systems of delegated middle management systems, with defined middle management roles and meetings with holders of these. Associated with this, Government heads spent more time dealing with internal issues. Non-Government heads, in contrast, spent more time addressing boundary issues, especially personal relations with 
trustees who played a more directly interventionist role than Government district officers to whom heads related primarily through written communication. More generally, Government heads saw themselves as having considerably less freedom to manage than did non-Government heads. In part, this arose from real differences in powers as described above. Beyond this, however, a more general sense emerged that Government heads were less likely to exhibit "performance efficacy," that is to say, a sense that "they are capable of improving student achievement through their deeds" (Chapman \& Burchfield, 1994, p. 406).

Our study (Simkins et al., 1998) raised some important issues about the work of heads in Pakistan. However, it was limited by its focus. Its emphasis on the day-to-day work of heads and their main role relationships inevitably led to an emphasis on the "maintenance" aspects of headship. Some information was obtained from the heads about their role in change management, and here too the non-Government heads seemed to have considered broader changes and taken more risks than had their Government colleagues. In general, however, the management of change was not the primary focus of the study. The emphasis was on the "what?" and the "how?" of headship rather than the "why?" This latter question raises key issues about the nature of leadership in Pakistani schools, and in particular the degree to which "transformational" leadership is attainable or appropriate.

Our second study took a rather wider view in two respects. First, it took a longitudinal approach by interviewing the heads three times over a period of some months. This enabled us to explore the heads' perspectives on the management of change, a key theme in many concepts of leadership as we have seen. Secondly, we drew on some interviews with teachers in each of the three schools, thus enabling us to access others' views of the leadership dimension of the head's role. The three heads were chosen as being representative of the three broad categories of school that are present in the city of Karachi, namely Government schools, private schools, and the network of schools belonging to the Aga Khan Education Service-Pakistan (AKES-P).

All three heads had participated in the Advanced Diploma in School Management (ADISM) offered by the Institute for Educational Development at the Aga Khan University (AKU-IED) in Karachi. Established in 1993, the AKU-IED initially concentrated on building a "critical mass" of "professional development teachers" who could facilitate change in their schools. However, when these teachers returned to their schools and attempted to lead other colleagues in taking action for improvement, they found their efforts 
frustrated, in many cases, by the lack of understanding of their work by headteachers. In response, AKU-IED created a programme for school leaders in which the latter were encouraged to re-think their assumptions about the role of headteachers and to acquire insights, knowledge, and skills to become the enablers of improvement in their schools. This programme became the Advanced Diploma in School Management (ADISM). At the end of the ADISM programme, headteachers are expected to devise an action plan for school improvement that they will implement over the succeeding 18 months. The three case studies were based on extended interviews carried out with the three headteachers over a period of 12 months as they sought to implement their plans. The initial interview was held immediately after the end of the Diploma programme. The second interview took place 6 months later and the final interview was held 12 months from the first. In each case, group interviews were also conducted with a small number of teachers from their school. This allowed us to gauge the "normality" of the headteacher's perception of school climate and progress. The next section describes the outcomes of this study.

\section{THREE HEADTEACHERS: SIMILARITIES AND CONTRASTS}

Farhat is our first case-study headteacher. She did not train as a teacher: her degree is in accountancy. She appears to have drifted into teaching initially at a high status private school where she taught for a number of years before leaving with the intention of quitting teaching. However, she was drawn back to work at a higher status school run by the same trustees as her present school and, after some time there, she felt a need to move on "to a school where there is more challenge, where people need me." Thus she came to her present community-based school, of some 1,600 pupils and situated in a deprived area. Farhat has been Principal for the past 5 years and the particular context of the school gives her a good deal of freedom to choose how she performs her role. Her relations with the board of trustees seem distant and ambiguous. Her main contact is with one individual whom she assumes to be the secretary who visits the school every 1 or 2 months but "he does not really monitor my performance. He may go round and see what is happening in school but basically I am the whole and sole authority." During her period at the school, it has more than doubled in size and there are plans to further increase the enrolment to more than 2,000 . 
Our second case study headteacher is Shiraz, who has been the headteacher for 18 months at his school, which is a Government boys' secondary school in the District Central of Karachi. He took over the role, having been a science teacher at the school for 15 years and then acting headteacher for 8 months. The school has 27 teachers but there is no management structure. Like nearly all Government schools in Pakistan, Shiraz has neither a deputy headteacher nor any middle managers. He had become the headteacher of his school when he reached a sufficient level of seniority in his District. In common with all state schools, Shiraz's school has no governing body or board of trustees. He reports and is directly responsible to the District Education Officer. Despite being in a deprived area, Shiraz's school is oversubscribed. He explained that this is because his school has a reputation for good discipline and better teaching standards than most schools in the District. This reputation results in Shiraz facing pressure from those who are politically powerful in the community, including education officials, to take students even if they live outside the official catchment area.

Nusrat, our third and final case study head, is currently the headteacher of the primary and pre-primary sections of a school which belongs to the Aga Khan Education Service network of schools in Pakistan (AKES-P). She has been at the school for 8 years, having previously been a deputy headteacher at another Aga Khan school in the city. There are 200 children in the pre-primary and 800 children in the primary sections of her school, which is situated in the heart of the city, close to the port area. In AKES-P the overall strategic direction of schools is determined by a Board of Management, with day-today leadership lying with a Chief Education Officer and, under him, a secondtier Chief Academic Officer responsible for schools in Karachi. The Board is expected to produce a development plan for all the schools in the service across the whole of Karachi. The plan is closely scrutinised by His Highness The Aga Khan and his advisory team. Plans for all the Aga Khan Foundation's social reform projects around the world have very strong central guidance concerning spiritual, social, and moral objectives. Schools are no different. The school has a management structure. Nusrat is responsible to a Principal. In her sections she has a deputy headteacher and five subject coordinators. Across the two sections, Nusrat leads a team of 30 teachers.

The strongest theme that emerges from the three cases is a shared commitment amongst the heads towards schools and pupils which operate in conditions of the utmost challenge. Not only do they all serve communities with significant economic deprivation, they also face challenges arising from 
broader factors such as the culture of violence which has arisen in parts of the city of Karachi during an extended period of political unrest. This commitment to their schools is reflected in Shiraz' case by more than 15 years of service to one school and in those of Farhat and Nusrat by a stated commitment to continue to serve their schools as they develop.

Similar perspectives on the challenges of these difficult circumstances run through all the interviews, not least the concern to establish a climate of discipline so that learning can take place. However, in each case this need is not articulated in terms of a disciplinarian leadership style, despite the pressures to act otherwise. The styles which these heads are attempting to implement are described in rather different ways. Thus Farhat speaks of giving respect to all:

At [this school] this is the one thing I have changed. ... I have never treated any teachers badly. At least in public I have never scolded anybody or said anything... I have always spoken politely and gotten the message around about politeness. I taught them that people are to be respected. ... I don't start screaming at the students also. I don't believe in that.

Shiraz speaks of friendship rather than dictatorship:

Because from the University I got the idea... That in order to get the cooperation of the staff, friendship is a better way compared to me dictating to them. I have become more democratic because, by experience, I reached the conclusion that in order to get improvement I must be more democratic.

Nusrat works in quieter ways:

I tried to understand everything... I took the staff positively... I didn't want to disturb the school... I told my officers...that I learn from them because I am new ... I don't know the office work ... I know how to teach, that's all... I took things very gradually and slowly...

However, each of them expresses the constant tension between authority and persuasion, the "hard" and the "soft" approach. This tension arises in part from the complexity of the challenges that these heads face. Simplistic leadership approaches are unlikely to be successful in such circumstances. Beyond this, however, tensions are created for each of them by the incessant social pressure to adopt a predominantly assertive, authoritarian or even disciplinary approach to leadership. The sources of these pressures vary somewhat from school to school as do their intensity. All the heads speak of teacher expectations in this regard. Thus Nusrat notes: "There were people 
who asked me, did you fire anybody when you went there?" Initially, against her better judgement, she tried to change her style of leadership, "but so many problems were created... so I had to revert back to my old quieter ways..." Farhat also alludes to deeply rooted community values in the locality of the school where violence and aggression seem to be a way of life: "Many times parents come to me and they say: 'Why don't you hit the child? If he is not behaving hit him.",

In these circumstances, adopting a leadership style that might be seen as countercultural is a substantial challenge. The motivation for doing so clearly varies: A strong personal philosophy about appropriate forms of behaviour in Farhat's case, shyness of personality in that of Nusrat, and learning from the Diploma course for Shiraz.

All the heads expressed positive attitudes towards change and all have implemented strategies of improvement in their schools, including in each case strategies focused on the classroom. However, it is here that the stories begin to diverge. Farhat clearly exemplifies many of the characteristics of the transformational leader as described earlier. She came to the school with a clear mission; she articulates a clear set of values which she attempts to instil in her staff both through discussion and direct modelling; and she positively revels in change - "I do like experiments ... I am very good at experiment" while recognising that her staff do not always find this commitment easy to cope with. However, she brings to her role a level of ascribed social status that appears to leave her unchallengeable in both the school and the community.

The parents, teachers, everybody has been quite supportive. They have never created problems as such... This whole community depends a lot on donations and charity and things like that and they think I have links. So they don't really, you know, mess about with me... The Board I think thinks I am doing them a favour by going there. ... So basically I have no obstacles.

Neither of the other heads can be described in quite these terms. Nusrat sees the importance of school improvement embodied in the policies of her trustees and the expectations of her principal:

His Highness (The Aga Khan) would rather like children to have the balance between economic and spiritual growth and he would like to see the school graduates to have the spiritual wisdom as well as educational growth ... I am personally in the habit of involving my superiors a lot... I take them into my confidence and feel comfortable like that. 
Shiraz, too, sees the need for change, but feels constrained about the possibilities both by the deadweight of the Government system and by the unresponsiveness of many teachers:

We must get help from the higher authority, this is one thing which can encourage us, but that encouragement is not there...no appreciation is there from any side and if I am doing something for the betterment of my students nobody will consider it a good thing.

I am discussing these ideas (for change and improvement) with staff at staff meetings but they say to me "we will do as you ask during the school hours but don't disturb us after school hours... Here everyone wants reward on the spot - no missionary sense will be there - no sense that "I am doing this for the betterment of the students."

Thus, for Farhat, school improvement is a personal challenge which she feels confident to lead, largely unaided; for Nusrat it is something which she feels committed to in response to the expectations and values of the education service for which she works; and for Shiraz improvement is an uphill struggle in which he receives little help or encouragement.

There seems little doubt that, for reasons described earlier, Shiraz, as a Government head, does indeed face greater challenges than his two colleague heads. Thus, while all emphasise the challenge of changing teacher skills, attitudes, and performance, especially at the classroom level, both Farhat and Nusrat have strategies available to them in this area which Shiraz cannot draw upon. Both have management structures which enable them to use coordinators to share the burden of teacher support and development, although each also gives examples of the constraints imposed when coordinators do not work in desired ways or attempt to block change. Both emphasise the importance of a critical mass of staff development underpinned by a culture which encourages this. Thus, Farhat speaks of:

Many teachers will tell you that they are sticking around in this school because of the changes which we have brought in. Because of the professional development that is there.

and Nusrat comments:

I feel that our higher management is trying to develop us more as leaders. They are trying to provide us with opportunities to come out and be more affected by talking to people... and I feel that it is very correct that the more effective we are then the more effective the staff would be. 
In contrast, there are few incentives for effective staff development in Shiraz' school:

There are no extra benefits of attending professional development programmes because there is no appreciation shown to us ... and if I am doing something for the betterment of my student nobody will consider it a good thing.

Even other headteachers “don't take professional development as a positive. They think that I am wasting my time. They are saying that I want to show myself up as better than them."

Again, reflecting earlier points, Nusrat relies on her school system's long tradition of professional development, whereas Farhat has had to establish and embed such a tradition. Shiraz in contrast, is mainly able to cite a series of constraints: inability to appoint or reward teachers, teachers' unwillingness to work outside standard hours, shortages of teaching staff, and other resources.

To summarise, the degree of personal efficacy demonstrated by the three heads is very different. Despite many personal reservations and uncertainties, Farhat's is high and derives from the confidence which arises from strong personal values and a social position that leads to an assumption that it is possible to make a difference. Nusrat, perhaps, could be characterised as seeing efficacy as a characteristic of the school system of which she is a part. Her underpinning personal values are strong, but in sofar as she pursues strategies of school improvement, these are seen as authorised and legitimised by the expectations of those for whom she works. Finally, Shiraz, like most heads of Government schools, is fighting to establish a sense of efficacy in a heavily constraining environment. The motivation is there, but the possibilities of significant movement are limited. All three heads, however, have found themselves constrained in their possibilities of action - especially the personal style that they can adopt - by broader cultural pressures, especially conceptions of leadership as requiring strength, assertiveness, and the imposition of hierarchical authority.

\section{CONCLUSION: THE DETERMINANTS OF EFFICACY}

The first stage of our research, involving interviews with six headteachers, emphasised the importance of differences between school systems in determining the opportunities and constraints which are placed on school 
heads in playing their roles. It emphasised, in particular, the debilitating effect of the culture of the Government system compared with others. However, the second stage - the three case studies - suggests a more complex picture. It suggests that national culture is an important variable in influencing leadership behaviour, but that this influence is mediated by system and personal factors.

There is clear evidence from all case studies that support Hofstede's finding that Pakistan's is a relatively high power distance culture. In such cultures there is a belief in the "naturalness" of hierarchy, subordinates exhibit a strong sense of dependence on their superiors and express "a preference for a boss who decides autocratically or paternalistically" (Hofstede, 1991, p. 27). Teachers and members of the community seem to expect all three heads to act decisively and relatively autocratically. Yet the dynamics of power distance and dependence operate differently in each school. For Farhat, the high degree of dependence on her which is expressed by others arises primarily not from her formal position but from her personal social status. This status, in turn, seems to inoculate her from any significant dependence on others. For Nusrat, in contrast, her position within the school hierarchy creates some degree of teacher dependence on her, although other factors - age? experience? personality? mean that not all her "subordinate" colleagues express equal degrees of dependence, while she herself expresses considerable dependence on her own bosses. Yet another situation appears to exist in the Government sector. Here Shiraz is locked into a formal hierarchical structure which might be expected to generate expectations of dependence, but in fact is heavily constrained by the counterdependent culture of the Government teaching service.

Similar analyses might be applied to other dimensions of cultural difference identified by Hofstede and others (Dimmock \& Walker, 1998; Hofstede, 1980, 1991), such as masculinity/femininity, individualism/collectivism, and uncertainty avoidance. More data than available from this study would be necessary to follow up these themes in more detail. Yet, on the basis of the studies reported here, it seems likely that a similarly complex picture would emerge. Thus, while national and community cultures create broad generic frameworks of expectations about leaders and leadership, these are contextualised through the cultural expectations generated and powers granted within particular school systems and further refined through individual headteacher's personal orientations which emerge from their histories and personalities. This suggests a three-dimensional model for exploring the possibilities of heads achieving personal efficacy as leaders in particular contexts (see Fig. 1). 


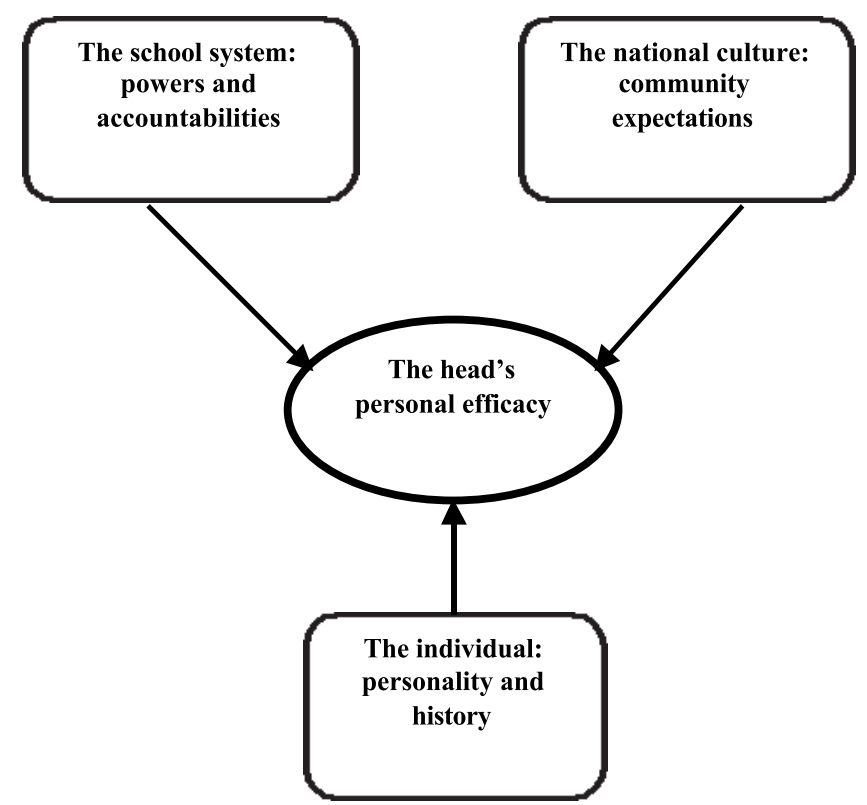

Fig. 1. Determinants of personal efficacy.

Despite their limited scale, these studies raise important issues in relation to our understanding of the nature of educational leadership across different national contexts. As yet our conclusions are tentative, but there are indicators here to suggest that, while we may indeed have much to offer each other from our different cultural settings and perspectives, we should move forward with great caution. Assumptions about the applicability of theories and models of effective leadership style and effective leaders from the West should be treated with a health warning attached. Context would seem to be a major determinant; and because contexts can be so culturally different, any attempt to translate notions and models of leadership, and in particular, successful leadership, from one context to another, is fraught with difficulties.

\section{ACKNOWLEDGEMENTS}

We wish to record our heartfelt thanks to the headteachers who gave their precious time and energy to participate in this study and who were prepared to reveal their thoughts and feelings about their roles as leaders of improvement. We are also grateful to all those colleagues in both 
our universities, who have, through countless conversations in all kinds of formal and informal settings, helped us in our efforts to tease out the complexities of headship and leadership in the schools of Karachi.

\section{REFERENCES}

Ali, M.A., Qasim, S.A., Jaffer, R., \& Greenland, G. (1993). Teacher-center and school-based models of collegiality and professional development: Case studies of the Teachers' Resource Center and the Aga Khan School System in Karachi, Pakistan. International Journal of Educational Research, 19(8), 735-754.

Bass, B.M. (1985). Leadership and performance beyond expectations. New York: Free Press. Burns, J.M. (1978). Leadership. New York: Harper and Row.

Chapman, D.W., \& Burchfield, S.A. (1994). How headmasters perceive their role: A case study in Botswana. International Review of Education, 40(6), 401-419.

De Grauwe, A. (2000). Improving school management: A promise and a challenge. International Institute for Educational Planning Newsletter, 18(4), 1-3.

Den Hartog, D.N., House, R.J., Hanges, P.J., Ruiz-Quintanilla, S.A., \& Dorfman, P.W. (1999). Culture specific and cross-culturally generalisable implicit leadership theories: Are attributes of charismatic/transformational leadership universally endorsed? Leadership Quarterly, 10(2), 219-256.

Department for International Development. (1999). Learning opportunities for all: A policy framework for education. London: Author.

Dimmock, C., \& Walker, A. (1998). Comparative educational administration: Developing a cross-cultural conceptual framework. Educational Administration Quarterly, 34(4), $558-595$.

Fuller, B., \& Clarke, P. (1994). Raising school effects while ignoring culture? Local conditions and influences of classroom tools, rules and pedagogy. Review of Educational Research, 64(10), 119-157.

Govinda, R. (Ed.). (1997). Decentralization of educational management: Experience from South Asia (Research Report 107). Paris: International Institute for Educational Planning.

Gronn, P. (1999). The making of educational leaders. London: Cassell.

Hallinger, P., \& Leithwood, K. (1996). Culture and educational administration: A case of finding out what you don't know you don't know. Journal of Educational Administration, 34(5), 98-116.

Hofstede, G. (1980). Culture's consequences: International differences in work-related values. London: Sage.

Hofstede, G. (1991). Culture and organizations: Software of the mind. New York: McGrawHill.

Koopman, P.L., Den Hartog, D.N., \& Konrad, E. (1999). National culture and leadership profiles in Europe: Some results from the GLOBE study. European Journal of Work and Organizational Psychology, 8(4), 503-520.

Lauglo, J. (1995). Forms of decentralization and their implications for education. Comparative Education, 31(1), 5-29. 
Leithwood, K., Tomlinson, D., \& Genge, M. (1996). Transformational school leadership. In K. Leithwood, J. Chapman, D. Corson, P. Hallinger, \& A. Hart (Eds.), International handbook of educational leadership and administration (Vol. 2, pp. 785-840). Rotterdam, The Netherlands: Kluwer.

Memon, M. (1998). The future of headteachers as educational leaders in Pakistan: Implications for pedagogic leadership. Education 2000, 3(3), 17-21.

Ribbins, P., \& Gronn, P. (2000). Researching principals: Context and culture in the study of leadership in schools. Asia Pacific Journal of Education, 20(2), 34-45.

Shaw, J. (1998). Cultural variations in management practice: An exploration of the management trainer's dilemma. Public Administration and Development, 18(4), 319-342.

Shaw, J., \& Welton, J. (1996). The application of education management models and theories to the processes of policy-making and management: A case of compound cross-cultural confusion. Paper presented at the 8th International Conference of the Commonwealth Council for Educational Administration and Management, Kuala Lumpur, Malaysia.

Simkins, T., Garrett, V., Memon, M., \& Nazir Ali, R. (1998). The role perceptions of Government and non-Government headteachers in Pakistan. Educational Management and Administration, 26(2), 131-146.

Southworth, G. (2002). Instructional leadership in schools: Reflections and empirical evidence. School Leadership and Management, 22(1), 73-91.

Stoll, L., \& Fink, D. (1996). Changing our schools: Linking school effectiveness and school improvement. London: Open University Press.

Therkildsen, O. (2000). Contextual issues in decentralization of primary education in Tanzania. International Journal of Educational Development, 20(5), 407-421.

Warwick, D.P., \& Reimers, R. (1995). Hope or despair? Learning in Pakistan's primary schools. Westport, CT: Praeger.

World Bank. (1995). Priorities and strategies for education: A World Bank Review. Washington, DC: Author. 